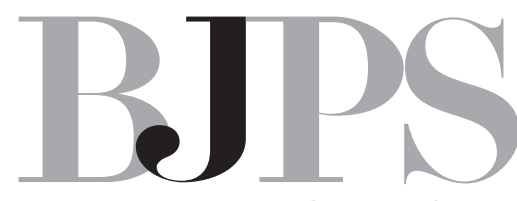

Brazilian Journal of

\title{
Pharmaceutical Sciences is in the agenda!
}

Pharmaceutical sciences is an area completely committed to the Health. It involves drugs in a wide sense, clinical analysis, diagnostic methods and also comprises food analysis and technology. Both in scientific and technological points of view, the innovation has been enormously emphasized in this area.

Nowadays, innovation is the keyword in Brazil in all fields. Actually, the development of the country depends on the technological advance and innovation is the leading means to achieve it. Nevertheless, there is a mismatch between the Brazilian science remarkable progress and the scarce development of technology in the country. This is a challenge that has to be faced and the Pharmaceutical area can, certainly, contribute to find part of the solutions for this problem.

The scenario today is quite favorable for Pharmaceutical Sciences. The universities and private initiatives, catalyzed by federal and state funding agencies, are coming closer for the benefit of society. Many programs launched by those segments have that profile and most of them succeeded.

The future seems to be fruitful depending on the willingness of both those developing researches in the field and those who have the expertise of transforming the generated knowledge into products that are useful for the improvement of health.

BJPS has published many papers reflecting the investment the funding organs have made in the researches coming from universities/research institutes and related to the Pharmaceutical Sciences. In its second year of the new police, the Journal, volume 46, received papers all over the country, mainly in the area of drugs and medicines, reporting pharmaceutics and quality control, among other topics. Those are areas that significantly match the pharmaceutical industries, many of them reflecting the investment of joint programs between public agencies and the private initiative. The quality of the papers published must be emphasized thanks both to the authors' expertise and to the seriousness and competence of the reviewers.

The Executive Editor, Leila Aranha, enormously contributed to the quality of publishing. The Assistant Editors and the members of the Editorial Board also had an important role in many aspects of BJPS publication.

Thanks also to the indexing bases as SciELO, Thomson Reuters ISI Web of Science, among others, and to the determinant support of CNPq, FAPESP and the Committee for Certification of USP Scientific 


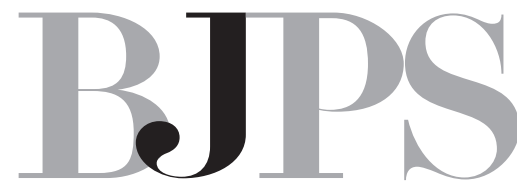

Brazilian Journal of Pharmaceutical Sciences

BRAZILIAN JOURNAL OF PHARMACEUTICAL SCIENCES

Periodical Publications, BJPS could be the scientific vehicle that exposes the potentiality of researches in contributing to the development of the country in the Pharmaceutical area.

As the Pharmaceutical Sciences is in the agenda, let us go for it!

Elizabeth Igne Ferreira

Scientific Editor 